\title{
A Contrastive Study of Resultative Constructions in English, Japanese and Chinese
}

\author{
Xiaowen Zhang \\ Tokyo Gakugei University, Japan; \\ Huaiyin Institute of Technology, China
}

\begin{abstract}
Researching on resultative constructions has become a hot topic in linguistic field in recent years, because it plays an important role in illuminating the nature of lexical semantics and its relationship with syntax. This paper simply contrasts resultative constructions in English, Japanese and Chinese from the perspectives of their syntactic structures and Washio's (1997) semantic distinctions, that is, strong resultatives and weak resultatives. I mainly discuss their similarities and differences to deepen our understanding of resultative constructions among these three languages. This paper is organized as follows: section 1 simply introduces types of resultative constructions in English, Japanese and Chinese; section 2 introduces Washio's analysis of strong and weak resultatives; section 3 compares $\mathrm{V}-\mathrm{V}$ compound resultatives in Japanese and Chinese to illustrate their differences; section 4 compares resultative constructions in three languages which are based on Washio's (1997) semantic analysis to identify the differences on resultatives in these three languages and furtherly explain why Japanese has only weak resultatives, according to Washio's analysis; section 5 is the conclusion of this paper.
\end{abstract}

Index Terms — resultative constructions, strong resultatives, weak resultatives

\section{Types of Resultative CONSTRUCTIONS In ENGLish, JAPANESE AND Chinese}

Resultative constructions refer to clauses in which, in addition to the main verb(V), there is a secondary predicate known as the result XP, consisting of an AP or PP. This XP denotes that the state described by the adjective or the preposition holds of the noun phrase as the result of the action denoted by the verb.

\section{A. Types of Resultative Constructions in English}

As to English resultatives, three types of resultative constructions are mainly introduced in this paper, namely, transitive resultatives, some examples cited from Washio (1997), as in (1); resultatives with unaccusative verbs, as shown in (2); resultatives with unergative verbs, examples cited from Washio (1997), as in (3).

(1) a. Mary shot John dead.

b. John hammered the metal flat.

c. Mary painted the wall white.

d. He broke the vase into pieces.

(1a) means that John was dead because Mary shot him. (1b) means that the metal became flat because of John's hammering it, and (1c) means that the wall became white because of Mary's painting it. (1d) means that the vase was in pieces because someone (he) broke it. From these examples, we can find that these sentences emphasize the description of a state that results from the action rather than simply describe the action typically denoted by the main verb.

(2) The lake froze solid.

In (2), freeze is an unaccusative verb. The D-structure of (2) is shown in the following. This sentence states the lake became solid because of freezing.

$\underline{e}$ froze the lake solid.

In this type of resultative constructions, the object NP is the subject of the resultative construction and the sentence denotes a change of state.

(3) a. Mary laughed herself stupid.

b. John danced his feet sore.

c. She worked herself sick.

In each of the examples under (3), the adjective modifies the object noun phrase and also specifies the state of the entity described by the noun phrase as a result of the action described by the main verb. But because the main verbs are intransitive, the syntactic objects in these resultatives are not the actual object of the main verb. For example, in (3c), she doesn't work 'herself'. The usage of the main verb involves more than the simple activity of working. From examples in (1-3), the word order of an English resultative construction is shown in (4):

$\begin{array}{rllll}\text { (4) a. S } & \mathrm{V} & \mathrm{O} & \mathrm{XP} & \text { (transitive) } \\ \text { b. S } & \mathrm{V} & \text { e } & \mathrm{XP} & \text { (intransitive) }\end{array}$

B. Types of Resultative Constructions in Japanese 
Compared with English, the formation of Japanese resultatives is more restricted. English resultatives can be divided into transitive and intransitive resultatives, but there are no intransitive resultatives in Japanese. Also, Japanese permits only certain series of transitive resultative constructions, rejecting other types which are possible in English. Examples cited from Washio (1997) in (1) correspond to Japanese resultatives in (5):

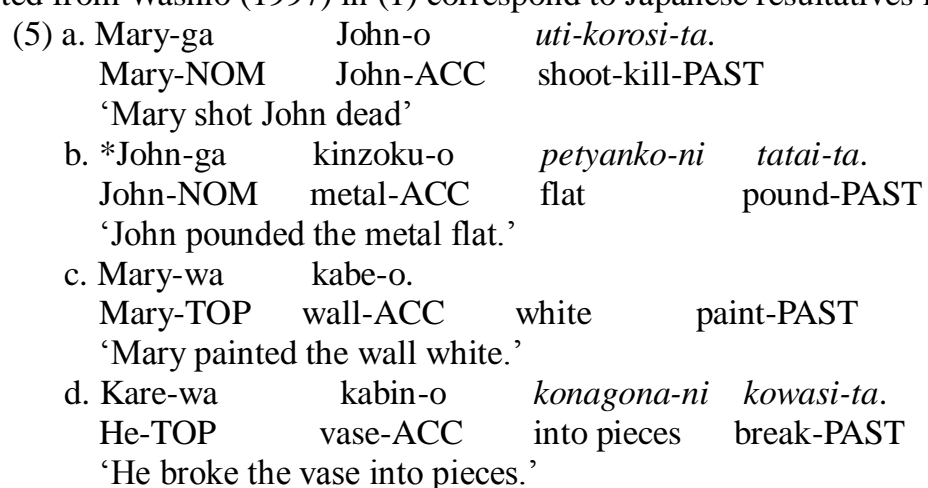

From examples (5a, c, d), we can observe that Japanese resultatives have two distinct constructions. Washio (1997) claims two strategies as shown in (6):

(6) a. $\mathrm{S} \quad \mathrm{O} \quad\left[\mathrm{v} \mathrm{V}_{1}-\mathrm{V}_{2}\right]$

b. S O ATP V

(6a) shows a complex verb strategy, corresponding to (5a), which is similar to Chinese V-V compounds. $V_{2}$ is the head of the entire verb, while $\mathrm{V}_{1}$ is a verb describing the simple activity, corresponding to the verb $\mathrm{V}$ in English resultative constructions. $\mathrm{V}_{2}$ is a causative change of state verb, which corresponds to the AP or PP in the English resultatives. Strategy (6b), on the other hand, is appropriate for $(5 c, d)$. The V in (6b) corresponds to the V in the English construction. Here, ATP stands for "Adjective-type Phrase", which has the same function with the AP/PP in English resultatives.

\section{Types of Resultative Constructions in Chinese}

Resultative constructions can be found in many languages, but resultatives in Chinese are a bit complicated. There appear to be two types of resultative constructions in Chinese: that is, V-V compounds and V-DE-(NP)-V constructions, as shown in (7) and (8), respectively. V-V compounds are constructed by compounding two verbal morpheme and these two verbal morphemes in each compound are in a clausal relation, with the one on the left (hereafter $\mathrm{V}_{1}$ ) indicating a causing event and the one on the right $\left(\mathrm{V}_{2}\right)$ indicating the resulting event. In the second type, V-DE-(NP)-V constructions, likewise, the first verb $\left(\mathrm{V}_{1}\right)$ is the cause; the second one $\left(\mathrm{V}_{2}\right)$, the result. The cause and the result are separated by a functional element DE.

(7) a. John pao lei le.

John run tired ASP

'John run tired,'

b. na tiao gou fei xing le wo mama.

That dog barked awake ASP my mother.

'That dog barked my mother awake.'

(8) a. John shui de yuntouzhuanxiang .

John sleep DE dizzy

'John slept and as a result he felt dizzy.'

b. na tiao gou fei de wo mama xing le. (V-DE-NP-V)

That dog barked DE my mother awake ASP

'That dog barked my mother awake.'

From examples (7-8), the word order of the Chinese resultative construction is shown in (9):

(9) the V-V compound
a. $\mathrm{NP}_{1} \quad \mathrm{~V}_{1}-\mathrm{V}_{2} \quad$ (intransitive)
b. $\mathrm{NP}_{1} \quad \mathrm{~V}_{1}-\mathrm{V}_{2} \quad \mathrm{NP} 2 \quad$ (transitive)
the V-DE-(NP)-V construction
c. NP1 V1-DE-V2 (intransitive)
d. NP1 V1-DE NP2 V2 (transitive)

\section{Strong Resultatives And Weak Resultatives in ENGLish}

Washio (1997) proposes the semantic distinctions between strong resultatives and weak ones. He gives the definition of strong resultatives, in which the main predicate doesn't entail the end state of the event and the resulting state is expressed only by AP or PP, for example (1b). In this sentence, the meaning of the verb hammer doesn't entail the final state of the object and the adjective word 'flat' expresses the resulting state. 
There is a special type of strong resultatives, in which the verb is unergative, as shown in (10):

(10) Mary danced her feet sore.

In (10), the verb dance is unergative, so it can not contain in its lexical semantics, anything like the notion sore denoted by the adjective that is predicated of the 'fake object'.

By contrast, there is a kind of resultatives in which the main predicate entails the end state of the event, which is described by the secondary predicate, as shown in (1c). In this sentence, the meaning of the verb paint entails the change of the wall's color; the adjectival result phrase white denotes the result phrase. Washio (1997) calls such sentences as weak resultatives. In short, in weak resultatives, verbs imply some change of state.

\section{The V-V COMPound TyPe OF Resultatives In JAPANESE AND ChinESE}

As to $\mathrm{V}-\mathrm{V}$ compounds in Japanese and Chinese, they are constructed by compounding two verbal morphemes and these two verbal morphemes are in a clausal relation. For example:

(11) a. Mary shot John dead.

b. Mary-ga John-o uti-korosi-ta. (Japanese)

Mary-NOM John-ACC shoot-kill-PAST

c. Mary she-si le John. (Chinese)

Mary shoot-die ASP John

In (11), we can find that the V-V compound uti-korosu in Japanese corresponds to 'shoot-kill' in English, while the $\mathrm{V}-\mathrm{V}$ compound she-si in Chinese corresponds to 'shoot-die' in English. So it appears that there are some differences on these V-V compounds between Japanese and Chinese.

\section{A. The Use of si 'Kill' in Chinese}

Tai (1984) argues that accomplishment verbs in English necessarily imply an achievement of the goal, while they do not necessarily so imply in Chinese. For example, the accomplishment verb 'kill' in English necessarily implies the death of the recipient of the action. Thus, (12) is ungrammatical in English.

(12) *Mary killed John, but he didn't die.

In dictionaries, the verb sha in Chinese is assumed to be equivalent to 'kill' in English. However, the verb sha does not imply the death of the recipient of the action, as shown in (13)

(13) Mary sha-le John liang-ci, ta dou mei si.

Mary kill-ASP John two-CL he all not die

'Mary killed John twice, but he didn't die.'

To guarantee the death of the recipient of the action, the V-V compound sha-si has to be used. sha-si is an action-result verb compound. Thus, the sentence in (14) is ungrammatical.

(14) *Mary sha-si-le John liang-ci, ta dou mei si.

Mary kill-die-ASP John two-CL he all not die

* Mary killed John twice, but he didn't die.

Vendler (1967) proposes that many of accomplishment verbs are expressed in Chinese by action-result verb compounds. For instance, 'find' in Chinese is zhao-dao 'seek-reach', 'receive' is shou-dao 'collect-reach,' 'see' is kan-dao 'look-reach,' and 'hear' is ting-dao listen-reach.' Most of them can function as transitive verbs. There is regarding the transitivity to identify the 'main verb' or 'head' in these compounds. The dominant view holds that the first verb representing action is 'main verb' or 'head', but a different view has been proposed by Tai (1984) which regards the second verb, or the so-called 'complement', as the 'head.' His view is the fact that the verb compound adjoined with $s i$ 'to die' illustrated in sentences (11) can be analyzed as 'cause to die'. Namely, as second verb of the compound, it is indeed equivalent to 'kill' in English. It functions as the center of predication, if not the main verb in surface syntax. However, the action verbs in these compounds, regardless of whether they are transitive or intransitive verbs, function like manner adverbs. In fact, the first verb of the compound with si doesn't have to be a verb by itself, as in (15) and (16). The Chinese word $d u$ in (15) cannot stand alone as a verb as illustrated in (16).

(15) Tamen Ju-si-le John. they poison-die-ASP John They killed John with poison.

(16) *Tamen $d u$-le John. they poison-ASP John They poisoned John.

According to Tai's (1984) proposal, in Chinese action-result verb compounds $\left(\mathrm{V}_{1}-\mathrm{V}_{2}\right), \mathrm{V}_{1}$ expresses the cause, but presents the subordinate event; whereas $\mathrm{V}_{2}$ expresses the result, but presents the main event. This fact shows the difference between Chinese and English. A problem arises as to how Japanese functions. For instance,

(17) Wo sha-le John liang-ci, ta dou mei si.

I kill-ASP John two-CL he all not die

* I killed John twice, but he didn't die.

* watasi-ga John-o nikai korosi-ta kedo, John-wa sina-naka-ta 
In (17), we may consider that Japanese is equivalent to English, whereas in fact such sentences exist in Japanese, as in (18):

(18) (kami-o) moeyasi-ta kedo, moe naka-ta.

* John burned it, but it didn't burn.

By Comparing (17) with (18), we find that it appears to have some similarities between V-V compounds in Chinese and Japanese, although Japanese is the same as English in the case of si 'kill'. Here, I want to refute Tai's (1984) view through some weak resultatives in Chinese. For example:

(19) a. John tu-bai le qiang.

John paint-white ASP wall

'John painted the wall white.'

b. Mary dong-ying le bingqiling.

Mary freeze-solid ASP ice cream

'Mary froze the ice cream solid.'

According to Washio's (1997) analysis, examples (19) belong to weak resultatives, which are permitted in Chinese. We know that the main verb in (19) is $V_{1}$ in the compound, not $V_{2}$, depending on the definition of weak resultatives that $\mathrm{V}_{1}$ entails the meaning of $\mathrm{V}_{2}$. In such sentences, $\mathrm{V}_{2}$ is just a predicate of $\mathrm{V}_{1}$ and represents the result. But this change is decided by its action verb $\mathrm{V}_{1}$.

\section{B. Syntactic Structures of V-V Compounds in Chinese and Japanese}

Although both Japanese and Chinese allow V-V compounds, there are some differences between these two languages. It is obvious that V-V compounds in Japanese appear to allow the pattern [action verb + causative verb], while Chinese seems to allow the pattern [action verb + state verb]. For example:

(20) a. Mary hit John dead.

b. Mary-ga John-o uti-korosi-ta. (Japanese)

Mary-NOM John-ACC hit-kill-PAST

c. Mary da-si le John. (Chinese)

Mary hit-die ASP John

*Mary da-sha le John.

Mary hit-kill ASP John

Also, Li Shen (2013) proposes that syntactic structures of V-V resultative compounds in Japanese and Chinese are different, as shown in (21).

(21) a.

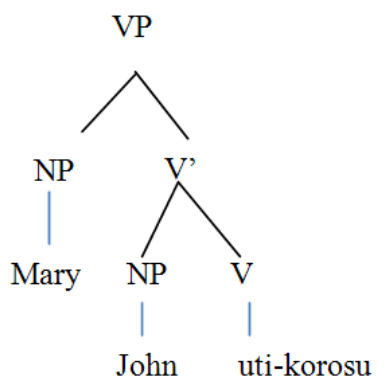

(shoot-CAUSE-kill) 
b.

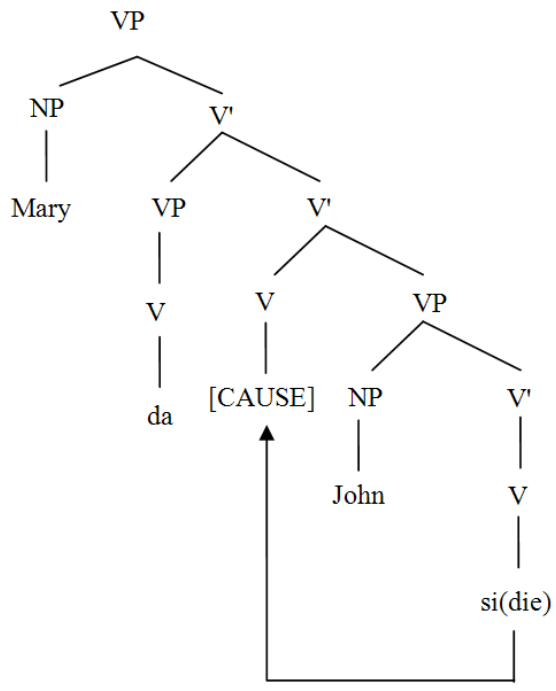

From their syntactic structures, Li Shen (2003) argues that <CAUSE $>$ in Japanese is overt, while it is covert in Chinese. In other words, in Chinese, $s i$ 'die' rises to the position of the covert $<$ CAUSE $>$ and compounds with $d a$ 'hit' to construct a V-V compound, da-si 'hit-dead'. On the contrary, without the movement, the V-V compound is constructed directly in Japanese. According to his analysis, we can say that Japanese V-V compounds are formed at the lexical level, while V-V compounds are formed at the syntactic level in Chinese. However, I consider that Li Shen's analysis is untenable. In Chinese linguistic field, the majority of linguists argue that V-V compounds are lexically-formed. On the other hand, I consider that V-V compounds in Japanese appear to have the similar syntactical structures with Chinese, as shown in (21b).

(22)

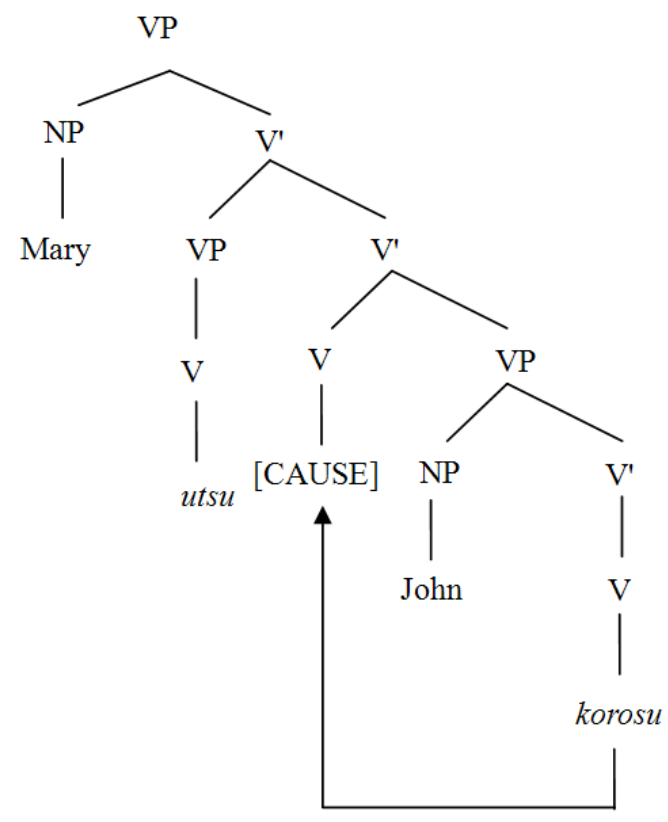

In (22), although V2 in Japanese V-V compounds is not the state verb, it is possible that <cause> in Japanese V-V compounds is covert. Through the above analysis, we find that V-V compounds in Chinese and Japanese are their similarities and differences, but it is argued that the formation of Japanese V-V compounds is more restricted than Chinese. In other words, Chinese V-V compounds are more easily formed than Japanese and play an important role in Chinese resultatives. For example:
(23) a. Zhangsan ku shi le shoupa. (Chinese)
Zhangsan cry wet ASP handkerchief
*Zhangsan-ga hankati-o naki-nui-da. (Japanese)
Zhangsan-NOM handkerchief cry-wet-PAST 
'Zhangsan cried the handkerchief wet.'

Here, a question arises as to why some Japanese V-V compounds are not allowed. In the following section, I will answer this question from the perspective of Washio's (1997) semantic distinctions between strong and weak resultatives.

\section{Semantic Distinctions AMOng English And JaPANESE AND Chinese}

Washio (1997) argues that resultative constructions can be divided into at least two types: strong and weak resultatives, according to the meaning of the main predicate. In section 3, I have introduced the definitions of strong and weak resultatives in English, for example:

(24) Strong resultatives in English

a. John hammered the metal flat.

b. Mary danced her feet sore.

Weak resultatives in English

c. John painted the wall white.

d. He froze the ice cream solid.

In (24), English has both strong and weak resultatives. We notice that in strong resultatives, the verb hammer in (a) is transitive, while the verb dance in (b) is unergative. In (a), the verb hammer doesn't imply any state of the patient that might result from the action it names. In (b), the verb dance cannot contain, in its lexical semantics, anything like the notion sore denoted by the adjective that is predicated of the 'fake object'. (c)-(d) are weak resultatives. In (c), the meaning of the verb paint entails the change of the wall's color; the adjectival result phrase white denotes the result phrase.

\section{A. Strong and Weak Resultatives in Chinese}

Like English, Chinese has also strong and weak resultatives. Here, many examples are shown to prove this fact. We know that Chinese appears to have two types of resultatives, that is, V-V compounds and V-DE-(NP)-V constructions. This paper argues that $\mathrm{V}-\mathrm{V}$ compounds in Chinese have not only strong resultatives but also weak resultatives, since in V-DE-(NP)-V constructions, maybe they have no weak resultatives. For example:

(25) Strong resultatives in V-V compounds
$\begin{array}{llll}\text { a. Lisi } & \text { ti-bian-le wo-de lanqiu. (transitive) } \\ \text { Lisi } & \text { kick-flat-ASP my basketball }\end{array}$
Lisi kick-flat-ASP my bas
b. Zhangsan ku-shi-le shoupa. (unergative)
Zhangsan cry-wet-ASP handkerchief
'Zhangsan cried the handkerchief wet.'

Weak resultatives in $\mathrm{V}-\mathrm{V}$ compounds

a. John tu-bai-le qiang.

John paint-white-ASP wall

'John painted the wall white.'

b. Ta dong-ying-le bingqiling.

$\mathrm{He}$ freeze-solid-ASP ice cream

'He froze the ice cream solid.'

On the other hand, Chinese is a bit different from English, because of the formation of V-V compounds in Chinese. The V-V compound in Chinese is widely used and their formations are not strictly restricted. In other words, some V-V compounds in Chinese cannot be interpreted as the corresponding English resultatives, as shown in (26).

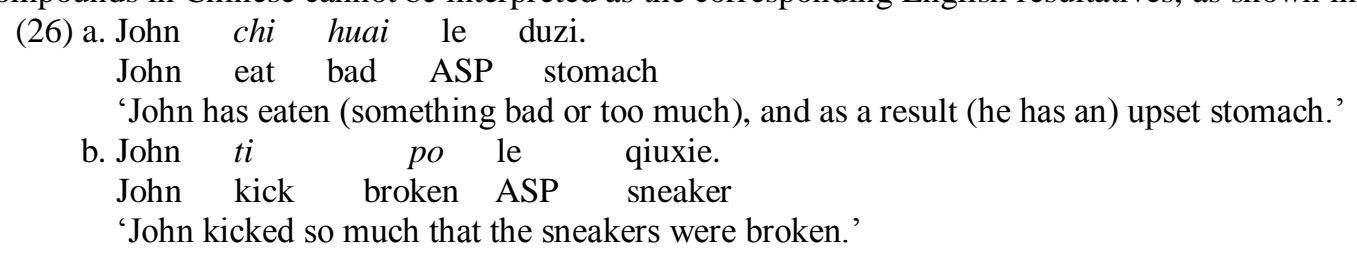

\section{B. Weak Resultatives in Japanese}

By Contrast, Japanese is very different from Chinese and English, which only allows weak resultatives. Furtherly, Japanese lacks intransitive resultatives and only allows some certain transitive resultatives. For example:
(27) a. *uma-ga maruta-o subesube-ni hikizut-ta. horse-NOM log-ACC smooth drag-PAST.
'The horse dragged the logs smooth.'
b. John-wa kabe-o siroku nut-ta. John-TOP wall-ACC white paint-PAST 'John painted the wall white.' 


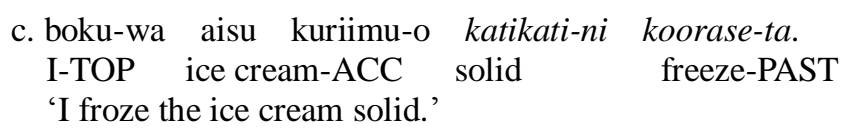

Here, a question arises as to why Japanese loses strong resultatives. As to this question, I want to analyze it from two perspectives: Path PP and Place PP in Japanese.

\section{Path PPs in Strong Resultatives}

Suzuki (2012) argues that covert Path PP is syntactically incorporated into V by the head-movement in strong resultatives, as shown in (28), but Japanese is a verb-framed language and Path PP is lexicalized in V, so it has no bounded Path PP, as shown in (29).

(28) The horses dragged the logs smooth.

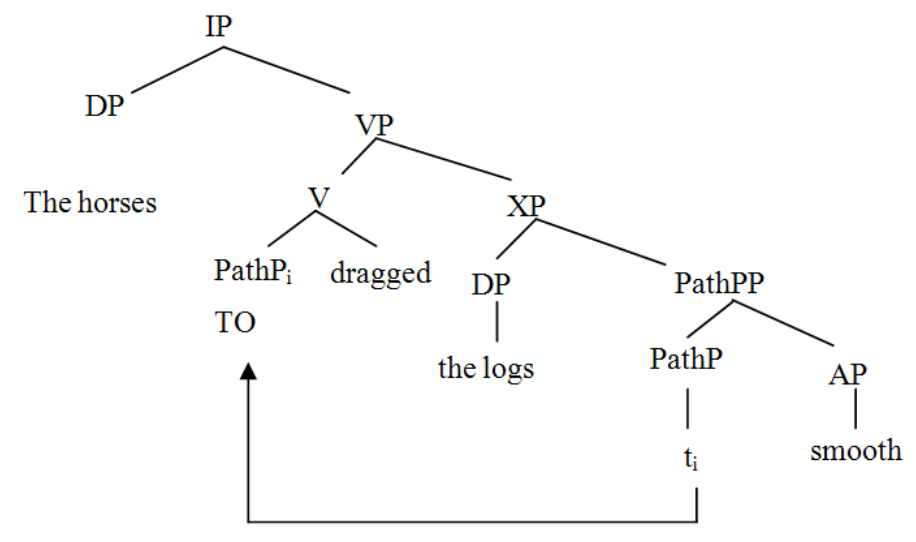

In (28), the empty Path PP selects AP 'smooth' for its complement, and then it is raised to V, so it might allow the non-spatial use of Path PP in strong resultatives.

(29) agaru: go up sagaru: go down

Thus, Japanese does not allow strong resultatives.

\section{Place PP in Weak Resultatives}

Chigusa (2009) proposes that the $u$-ending form of an adjective consists of the adjectival stem ending with the consonant $/ \mathrm{k} /$ and the adverbial suffix $-u$ and here $-u$ is a noun in Japanese, so the u-ending form of an adjective constitutes a NP, which is attached by the null P head to become a PP. According to her proposal, the result phrase siroku in $(27 \mathrm{~b})$ has the following structure:

(30) $[\mathrm{PP}[\mathrm{NP}[\mathrm{AP}$ sirok $]-\mathrm{u}]-\Phi] \quad(\Phi$ refers to the null P)

$$
\text { white }-\mathrm{N}-\mathrm{Adv} \quad \text { (Chigusa (2009)) }
$$

Because nominals in Japanese are case-marked, according to the case filter theory, NPs in Japanese must be a case-marking head. The $u$-ending form of an adjective in resultatives is a complement of a NP, so I assume that it is supported by the null $\mathrm{P}$ head. Therefore, the $u$-ending form of an adjective in Japanese resultative constructions is a PP, as illustrated in (30).

Some examples are given to prove her assumption, as shown in (31):

(31) a. kanojo-wa gakko-no chikak-u-ni sundeiru. She-TOP school-GEN near-U-at is living.

'She lives near the school.'

b. kanojo-wa yuushoku-o hayak-u-kara junbi-sita.

She-TOP supper-ACC early-U-from preparation-PAST

'She prepared for supper from early.'

The examples in (31) show that the $u$-ending form of an adjective is followed by the prepositions $-n i$ 'at' in (31a) and -kara 'from' in (31b). Examples in (31) support the proposal that the $u$-ending form of an adjective can constitute a NP, because the preposition can only take a nominal complement in Japanese.

Here, a question arises as to whether PP is Place PP or Path PP in Japanese weak resultatives. As Jackendoff (1983) points out, locative PPs denote sets of Places (locations) in semantics, whereas directional PPs denote sets of Paths made up of Places. And Koopman (1997) claims that locative PPs are associated with Place structure, directional PPs with Path structure which embeds Place structure in syntax. Locative PPs can be complements of stative verbs like $b e$, stay, remain, as shown in the following sentences (a. The box was in / on / under / behind the table. b. *The box was to / into / onto / from / out of / through the table.), whereas Directional PPs express some kind of trajectory along which an entity moves or is moved rather than a location that describes a state of an entity. In short, we can call locative PPs Place PPs and directional PPs Path PPs. Based on the semantic meaning and syntactic structure of Place PP and Path PP, I argue that PP refers to Place PP in Japanese weak resultatives in (27b), for example: gakkou (ni) iku'go to school'. As to the interpretation of this sentence in Japanese, except for the translation $n i$ as Path $\mathrm{P}$ 'to', there is another 
interpretation. If PP in (27b) is interpreted as Path PP, it is contradictory with the fact that there are no strong resultatives in Japanese, since Path P only exists in strong resultatives, as Suzuki (2012) proposed.

\section{CONCLUSION}

Based on Washio's (1997) semantic distinction between strong and weak resultatives, this paper simply discusses the similarities and differences among English and Japanese and Chinese by contrasting them from the perspectives of syntax and semantics. Also, the question why Japanese only allows weak resultatives is discussed. It is analyzed from two aspects: Place PP and Path PP. Of course, during whiting this paper, some problems appear, that is, the differences on syntactic structures of V-V compounds in Chinese and Japanese are not explained on details; this paper does not discuss the V-DE-(NP)-V construction in Chinese from Washio's strong and weak resultatives. On my future research, these problems will be focused on.

\section{REFERENCES}

[1] Chigusa, Morita. (2009). A Crosslinguistic Observation of Resultative Constructions. Linguistic Research 25. 43-55.

[2] Jackendoff, R. (1983). Semantics and Cognition. MIT Press, Cambridge, MA.

[3] Koopman, Hilda. (1997). Prepositions, Postpositions, Circumpositions and Particles: The Structure of Dutch PPs. Ms. UCLA.

[4] Li Shen. (2013). A comparative analysis of resultative verbal compounds in Chinese and Japanese: Compounding in syntax and lexicon. Mysteries of Verb-Verb Complexes in Asian Language 14-15.

[5] Suzuki, T. (2012). Strong Resultative as a PathP Construction. Coyote Papers 20. Univ. of Arizona.

[6] Tai, James H-Y. (1984). Verbs and Times in Chinese: Vendler's Four Categories. Parasession on Lexical Semantics 20: $289-296$. Chicago: Chicago Linguistic Society.

[7] Vendler, Zeno. (1976). Linguistics in Philosophy. Ithaca: Cornell University Press.

[8] Washio, Ryuichi. (1997). Resultatives, compositionality and language variation. Journal of East Asian Linguistics 6. 1-49.

Xiaowen Zhang, female, was born in Huaian, China in 1984. She is studying for her PH.D. degree in linguistics in Tokyo Gakugei University of Japan now. She is also an English teacher of Huaiyin Institute of Technology in Huaian of Jiangsu Province. Her research interests include English linguistic, American literature, and English education. 